\title{
Kinetics of Initial Stage of the Thermal Dehydrochlorination of Poly(vinyl chloride)
}

\author{
B. B. Troitskit, L. S. Troitskaya, V. N. Denisova, and Z. B. Luzinova \\ Institute of Chemistry, Academy of Science of U.S.S.R., Gorkii, U.S.S.R.
}

(Received May 18, 1977)

\begin{abstract}
Dehydrochlorination of poly(vinyl chloride) (PVC) under vacuum (about $10^{-4} \mathrm{mmHg}$ ), with continuous removal of volatile products by freezing out, has been studied at $200^{\circ} \mathrm{C}$. A quantitative treatment of the scheme of consecutive reactions of PVC degradation in vacuo has been carried out. The contributions of each of the two processes of dehydrochlorination (that initiated by decomposition of unstable groups present in the original PVC and of normal links of macromolecules) into the overall rate of polymer degradation were estimated. Investigations were made on the effects of mild chlorination of PVC by chlorine in the dark and in sunlight at $20^{\circ} \mathrm{C}$ and of treatment of $\mathrm{PVC}$ at $80^{\circ} \mathrm{C}$ or $150^{\circ} \mathrm{C}$ by some compounds (tributyl phosphite, and its mixture with dibutyltin dichloride; bis(butyl maleate)-, bis(octyl maleate)-, bis(butyl thioglycolate) of dibutyltin; triethylsilicon, triethylgermanium, and mixtures of hydrides with dibutyltin dichloride) upon the rate of dehydrochlorination of the polymer in vacuo. It has been shown that the initial rate of degradation in vacuo decreases considerably only after treatment of PVC by mixtures of Si- or Ge-organic hydrides with dibutyltin dichloride.
\end{abstract}

KEY WORDS Poly(vinyl chloride)/Kinetics of Thermal Dehydrochlorination / Initial Stage / Treatment / Chlorine / Organic Phosphites/ Metallo-organic Hydrides /

In recent years, the mechanism of the thermal degradation of poly (vinyl chloride) (PVC) has been intensively studied. ${ }^{1-9}$ In the presence of volatile products, the thermal dehydrochlorination has an autocatalytic character, connected with the accelerating effect of $\mathrm{HCl}^{1-5,10-14}$

The thermal degradation of PVC in the presence of $\mathrm{HCl}$ is generally believed to proceed by an ionic or molecular-ionic mechanism. Different reaction schemes have been proposed..$^{2-5,12,14}$

It was shown ${ }^{4,11,12}$ that the catalytic effect of $\mathrm{HCl}$ is connected with its interaction with the polyene units produced in the macromolecules. Therefore the following scheme ${ }^{4}$ is probable.

$$
\begin{gathered}
\sim(\mathrm{CH}=\mathrm{CH})_{n}-\underset{!}{\mathrm{CH}}-\mathrm{CH}_{2} \sim+\mathrm{HCl} \\
\mathrm{Cl} \\
\longrightarrow \sim(\mathrm{CH}=\mathrm{CH})_{n}-\underset{\oplus}{\mathrm{CH}}-\mathrm{CH}_{2} \sim \\
\sim(\mathrm{CH}=\mathrm{CH})_{n} \sim+2 \mathrm{HCl} l_{2} \ominus \\
\longrightarrow \sim(\mathrm{CH}=\mathrm{CH})_{n-1}-\underset{\oplus}{\mathrm{CH}}-\mathrm{CH}_{2} \sim \\
\stackrel{\mathrm{HCl}}{\longrightarrow}
\end{gathered}
$$

$$
\begin{aligned}
& \sim(\mathrm{CH}=\mathrm{CH})_{n}-\underset{\oplus}{\mathrm{CH}}-\mathrm{CH}_{2} \sim \\
& \mathrm{HCl}_{2} \ominus \\
& \stackrel{\mathrm{PVC}}{\rightleftarrows} \sim(\mathrm{CH}=\mathrm{CH})_{n}-\underset{\oplus}{\mathrm{CH}}-\mathrm{CH}_{2} \sim+\mathrm{HCl}_{2} \ominus
\end{aligned}
$$

Apparently, ionic pairs form owing to polarization of the $\mathrm{C}-\mathrm{Cl}$ allylic links under the influence of $\mathrm{HCl}$ (eq 1) or due to the transfer of an electron from conjugated double bonds to $\mathrm{HCl}$ molecules (eq 2). Ionic pairs cause PVC dehydrochlorination by a chain ionic mechanism.

In the thermal degradation of PVC with continuous and effective removal of $\mathrm{HCl}$ from the reaction zone, autocatalysis does not occur. ${ }^{4-6,10-13}$ The thermal dehydrochlorination of PVC under vacuum with continuous removal of $\mathrm{HCl}$ is believed to proceed by a molecular mechanism. ${ }^{3-5}$

This paper deals with the kinetics of the initial stage of the thermal dehydrochlorination of PVC in vacuo and with the influence of treatment of the polymer by various compounds on the initial rate of PVC degradation under vacuum. 


\section{EXPERIMENTAL}

\section{Materials}

Two samples of suspension PVC were used. PVC-I was prepared by suspension polymerization at $36^{\circ} \mathrm{C}$ of a monomer-water mixture at a ratio $1: 2$ with methyl cellulose as emulsifier $(0.035 \%)$ and dicyclohexylperoxydicarbonate $(0.1 \%)$ as initiator. PVC-II was the commercial polymer (S-63).

The polymers were twice precipitated from absolute tetrahydrofuran into absolute 2-propanol and dried for $60 \mathrm{hr}$ at $40^{\circ} \mathrm{C}$ under reduced pressure.

The intrinsic viscosity of PVC-I measured in cyclohexanone at $30^{\circ} \mathrm{C}$ was $1.67 \mathrm{~d} / / \mathrm{g}$. The molecular weight of PVC-I was calculated to be $1.5 \times$ $10^{5}$ from the $[\eta]-M_{w}$ relationship reported by Kinney. ${ }^{15}$

Sizes of polymer particles were less than $0.25 \mathrm{~mm}$.

Gaseous $\mathrm{Cl}_{2}$ was prepared by a literature method $^{16}$ and purified by repeated freezing, evacuating, and thawing.

Tributyl phosphite (TBP) was prepared by a litarature $\operatorname{method}^{17}:$ bp $94^{\circ} \mathrm{C}(2 \mathrm{~mm}) ; n_{\mathrm{D}}^{20} 1.4321$ (lit. ${ }^{17} n_{\mathrm{D}}^{20} 1.4321$ ).

Organo-tin compounds were prepared by known methods. ${ }^{18}$ Dibutyltin dichloride (DBTDC), mp $42^{\circ} \mathrm{C}$ (lit. ${ }^{18} \mathrm{mp} 43^{\circ} \mathrm{C}$ ).

Dibutyltin bis(butyl thioglycolate) (DBTBBT), $\left(\mathrm{C}_{4} \mathrm{H}_{9}\right)_{2} \mathrm{Sn}\left(\mathrm{SCH}_{2} \mathrm{COOC}_{4} \mathrm{H}_{9}\right)_{2}, n_{\mathrm{D}}^{20}$ 1.5187. Anal. Calcd for $\mathrm{C}_{20} \mathrm{H}_{40} \mathrm{O}_{4} \mathrm{~S}_{2} \mathrm{Sn}$ : C, 45.55; H, 7.64; $\mathrm{Sn}$, 22.51; S, 12.16. Found: C, 45.57; H, 7.86; Sn, 23.19; S, 10.54 .

Dibutyltin bis(butyl maleate) (DBTBBM), $\left(\mathrm{C}_{4} \mathrm{H}_{9}\right)_{2} \mathrm{Sn}\left(\mathrm{OOCCH}=\mathrm{CHCOOC} \mathrm{H}_{9}\right)_{2}, n_{\mathrm{D}}^{20} \quad 1.4865$. Anal. Calcd for $\mathrm{C}_{24} \mathrm{H}_{40} \mathrm{O}_{8} \mathrm{Sn}$ : C, 50.11; H, 7.01; $\mathrm{Sn}, 20.63$. Found: C, 50.00; H, 7.05; Sn, 20.39.

Dibutyltinbis (octyl maleate) (DBTBOM), $\left(\mathrm{C}_{4^{-}}\right.$$\left.\mathrm{H}_{9}\right)_{2} \mathrm{Sn}\left(\mathrm{OOCCH}=\mathrm{CHCOOC} \mathrm{H}_{17}\right)_{2, n} \quad n_{\mathrm{D}}^{20} \quad 1.4825$. Anal. Calcd for $\mathrm{C}_{32} \mathrm{H}_{56} \mathrm{O}_{8} \mathrm{Sn}$ : C, 55.91; $\mathrm{H}, 8.21$; Sn, 17.26. Found: C, 56.22; H, 8.28; Sn, 16.91.

Triethylsilicon and triethylgermanium were prepared by methods decribed in ref 19, 20. Triethylsilicon (TES), $\left(\mathrm{C}_{2} \mathrm{H}_{5}\right)_{3} \mathrm{SiH}$, bp $107^{\circ} \mathrm{C}$ (lit. $\left.{ }^{19} 107.7^{\circ} \mathrm{C}\right) ; \quad n_{\mathrm{D}}^{20} 1.4125$ (lit. $^{19} n_{\mathrm{D}}^{20} 1.4117$ ). Triethylgermanium (TEG), $\left(\mathrm{C}_{2} \mathrm{H}_{5}\right)_{3} \mathrm{GeH}$, bp $122^{\circ} \mathrm{C}$ (lit. ${ }^{20}$ bp $122^{\circ} \mathrm{C}$ ); $n_{\mathrm{D}}^{20} 1.4330$ (lit. ${ }^{20} n_{\mathrm{D}}^{20} 1.4330$ ).

\section{Methods}

Degradation of PVC with removal of $\mathrm{HCl}$ was investigated at $200^{\circ} \mathrm{C} \pm 0.5^{\circ} \mathrm{C}$ in evacuated $\left(10^{-4}\right.$ $\mathrm{mm}$ ) sealed ampoules with side-arms. The volatile products were continuously frozen into the sidearms by liquid nitrogen. The amount of evolved $\mathrm{HCl}$ was determined by titration according to Volhard' method. 0.05- $\mathrm{N}$ aqueous solutions of $\mathrm{AgNO}_{3}$ and $\mathrm{NH}_{4} \mathrm{CNS}$ were used. A $250 \pm 0.5$-mg portion of PVC-I and a $50 \pm 0.1-\mathrm{mg}$ portion of PVC-II were used for each experiment.

Treatment of PVC by various compounds was carried out at $80^{\circ} \mathrm{C}$ or $150^{\circ} \mathrm{C}$ for $2-5 \mathrm{hr}$ in evacuated (up to about $10^{-2} \mathrm{~mm}$ ) sealed ampoules in which $1.5-2.0 \mathrm{~g}$ of PVC-I and $10 \mathrm{~mol} \%$ of compound were charged. After treatment, the polymer was twice precipitated from absolute tetrahydrofuran into absolute ethanol and dried for $50 \mathrm{hr}$ at $40^{\circ} \mathrm{C}$ under reduced pressure.

Mild chlorination of PVC was carried out at $20^{\circ} \mathrm{C}$ in the dark and in sunlight for times from 30 min to $100 \mathrm{hr}$ in $4-l$ vacuum desiccator which was evacuated (up to about $10^{-2} \mathrm{~mm}$ ) and then filled up by purified $\mathrm{Cl}_{2}$ up to $300-400 \mathrm{~mm}$. $1.5-2.0-\mathrm{g}$ portions of powdered samples of PVC were used. The polymer was split into thin layers in Petri dishes. After chlorination, the desiccator was evacuated for $2 \mathrm{hr}$. Then the polymer was transferred to another desiccator in which dishes with $\mathrm{KOH}$ and $\mathrm{CaCl}_{2}$ were placed also. This desiccator was evacuated and left for $10 \mathrm{hr}$. Then the polymer was carried from the desiccator to the vacuum drying cabinet and evacuated at $40^{\circ} \mathrm{C}$ for $50 \mathrm{hr}$ under reduced pressure.

\section{RESULTS AND DISCUSSION}

Figure 1 shows a typical kinetic curve (curve 1) for dehydrochlorination of PVC under conditions excluding autocatalysis [high vacuum $\left(10^{-4}-\right.$ $10^{-5} \mathrm{~mm}$ ), continuous removal of volatile products by freezing out by liquid nitrogen, small thickness of layer of powdered polymer purified by double reprecipitation] when the thermal degradation proceeds in the kinetic field and is not limited by diffusion of $\mathrm{HCl}^{4-6,10,12,13,21}$

It has been shown ${ }^{5,6,21}$ that the kinetic curve of PVC degradation at $180-200^{\circ} \mathrm{C}$ in the initial stage (Figure 1, curve 1) may be separated into two curves, 2 and 5 (Figure 1) which are described by 


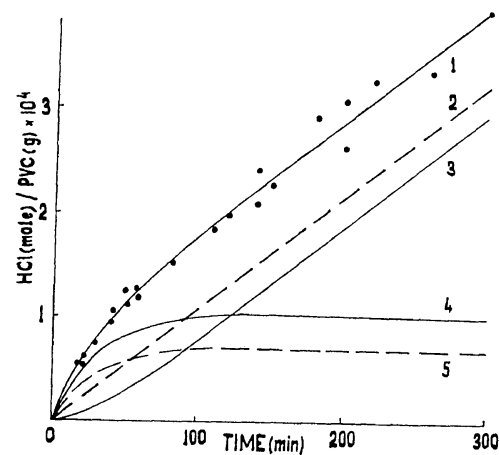

Figure 1. Kinetic curve of dehydrochlorination of PVC-I in vacuo (about $10^{-4} \mathrm{~mm}$ ) at $200^{\circ} \mathrm{C}$ with continuous removal of $\mathrm{HCl}$ (1), separated into curves 2 and 5. Curves 3 and 4 are calculated from eq 16 and 17 at $k_{0}=10^{-6.84} \mathrm{sec}^{-1}, k_{1}=10^{-3.34} \mathrm{sec}^{-1}$, and $l_{\mathrm{av}}=8$.

equations for first-order reaction with the following effective rate constants.

$$
\begin{aligned}
& k_{0}^{\mathrm{ef}}=10^{11.8 \pm 0.5} \times \exp (-38000 \pm 1000 / R T) \mathrm{sec}^{-1} \\
& k_{\mathrm{a} 11}^{\mathrm{ef}}=10^{9.6 \pm 0.5} \times \exp (-28000 \pm 1000 / R T) \mathrm{sec}^{-1}
\end{aligned}
$$

From Figure 1, it is seen that overall process of PVC dehydrochlorination consists of two processes, viz., degradation of unstable groups present in the virgin polymer (eq 5) and of more stable fragments (eq 4).

There has been considerable discussion ${ }^{1-3,7-9,22-38}$ about the nature and concentration of unstable units of $\mathrm{PVC}$ macromolecules such as $\sim \mathrm{CH}_{2}-\mathrm{CH}=$

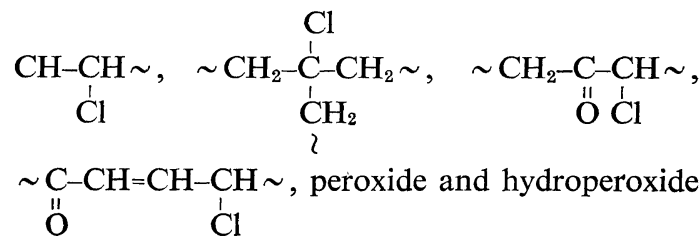

groups which remain in PVC after polymerization or are produced by oxidation of allylic or tertiary hydrogen atoms and residual monomer.

The quantity of unstable groups in PVC depends on the method of production, isolation, and storage of the polymer. Various authors ${ }^{27-33}$ found different values of concentrations of particular unstable fragments (from 0.01 up to $\sim 0.1 \mathrm{~mol} \%$ ) depending on the experimental procedure.

Data $^{31,37}$ showing a decrease of the rate of degradation after mild chlorination strongly sug- gested the considerable influence of chloroallylic fragments in the original PVC on the stability of the polymer. It is known ${ }^{31}$ that first of all mild chlorination of PVC results in addition of chlorine to double bonds. In previous papers ${ }^{31,37}$ the methods of chlorination are not explained in detail, therefore we could not reproduce the same experimental conditions.

Two samples of suspension PVC were used for chlorination. From the kinetic curves of dehydrochlorination of these polymers (Figure $2 \mathrm{a}, \mathrm{b}$ ) one can conclude that PVC-II contains more unstable groups than PVC-I. But we cannot define quantitatively each type of anomalous structures because there are no reliable methods.
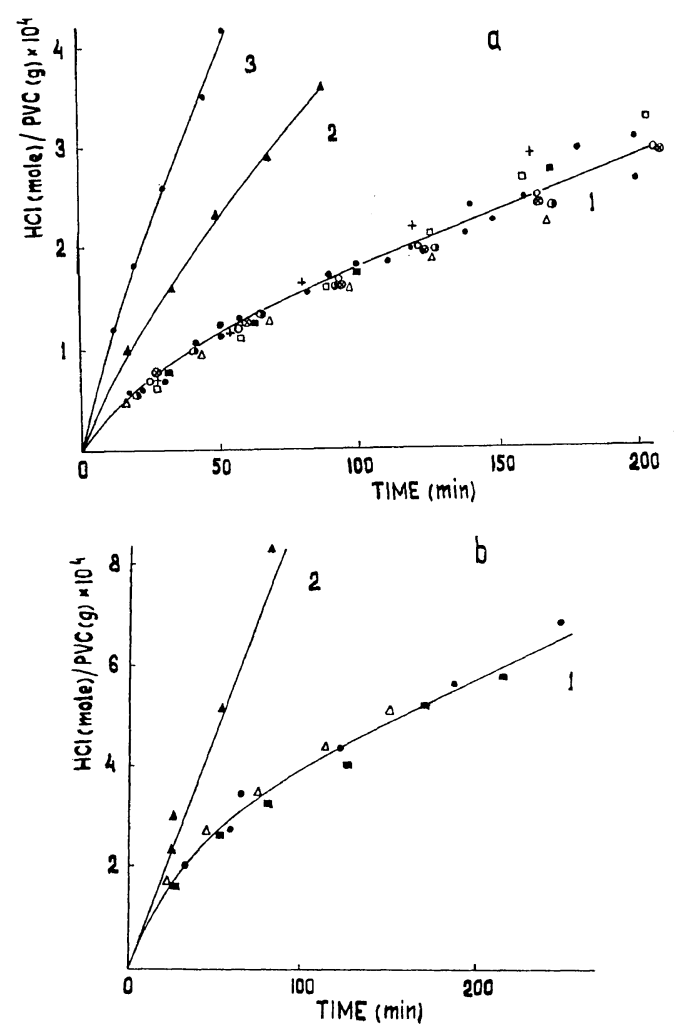

Figure 2. Effect of mild chlorination of PVC-I (a) and PVC-II (b) on the rate of dehydrochlorination of the polymer in vacuo (about $10^{-4} \mathrm{~mm}$ ) at $200^{\circ} \mathrm{C}$ with continuous removal of $\mathrm{HCl}$ : (1) original PVC (e) and PVC treated with chlorine in the dark at $20^{\circ} \mathrm{C}$ for $0.5 \mathrm{hr}$ (○), $2 \mathrm{hr}(\otimes), 18 \mathrm{hr}(\circlearrowleft), 24 \mathrm{hr}(\triangle), 45 \mathrm{hr}(\square), 92 \mathrm{hr}(\mathbf{\square})$, and $96 \mathrm{hr}$ in the presence of $\mathrm{HCl}(+)$; (2) and (3), PVC treated with chlorine in sunlight at $20^{\circ} \mathrm{C}$ for $2 \mathrm{hr}(2)$ and $24 \mathrm{hr}(3)$. 
Table I. Elementary analysis of PVC-I before and after treatment by mixture of $10 \mathrm{~mol} \%$ of TES or TEG with $1 \mathrm{~mol} \%$ of DBTDC at $150^{\circ} \mathrm{C}$ for $4 \mathrm{hr}$ and after mild chlorination of the polymer in the dark at $20^{\circ} \mathrm{C}$ for $92 \mathrm{hr}$

\begin{tabular}{lccc}
\hline \multirow{2}{*}{ PVC } & \multicolumn{3}{c}{ Elementary analysis } \\
\cline { 2 - 4 } & $\mathrm{C}$ & $\mathrm{H}$ & $\mathrm{Cl}$ \\
\hline Original & 38.22 & 5.10 & 56.68 \\
After treatment by & & & \\
TES +DBTDC & 38.71 & 5.17 & 56.12 \\
After treatment by & & & \\
TEG +DBTDC & 39.31 & 5.28 & 55.41 \\
After mild chlorination & 38.32 & 4.79 & 56.89 \\
\hline
\end{tabular}

We carried out mild chlorination of PVC by purified chlorine in the dark and in sunlight for times from $30 \mathrm{~min}$ to $100 \mathrm{hr}$, but did not observe any decrease of the degradation rate in vacuo with removal of $\mathrm{HCl}$ (Figure $2 \mathrm{a}, \mathrm{b}$ ). Table I shows that even after chlorination of PVC in the dark for $92 \mathrm{hr}$ no marked increase of chlorine content occurs.

Apparently, there is not enough data to make definite conclusions about the contribution of each type of unstable group present in the original polymer to the initial rate of degradation; in this direction further investigations are necessary. One can maintain that some different irregular fragments simultaneously affect the initial rate of dehydrochlorination, but not that any single group does.

The normal links of macromolecules are considerably more stable groups. It has been shown $^{6,21}$ that the thermal degradation of PVC at higher temperatures, viz., $220-250^{\circ} \mathrm{C}$ is well described by eq 4 up to about $60 \%$ conversion. At these temperatures, one can neglect the contribution of the degradation of unstable fragments in original PVC to the overall rate of dehydrochlorination of the polymer.

Figure 1 indicates that the initiation of the thermal degradation of PVC under vacuum with continuous removal of volatile products proceeds by two reactions namely degradation of normal links and of unstable fragments present in the original polymer.

The thermal degradation of PVC by a molecular-ionic mechanism may be described by the following equations.
Initiation:

$$
\begin{aligned}
& \sim \mathrm{CHCl}-\mathrm{CH}_{2}-\mathrm{CHCl}-\mathrm{CH}_{2} \sim \\
& \quad \stackrel{k_{0}}{\rightarrow} \sim \mathrm{CH}=\mathrm{CH}-\mathrm{CHCl}-\mathrm{CH}_{2} \sim+\mathrm{HCl} \\
& \quad \mathrm{UF} \stackrel{k_{0}}{\longrightarrow} \sim \mathrm{CH}=\mathrm{CH}^{*}-\mathrm{CHCl}-\mathrm{CH}_{2} \sim+\mathrm{HCl} \\
& \sim \mathrm{CH}=\mathrm{CH}^{*}-\mathrm{CHCl}-\mathrm{CH}_{2} \sim \\
& \stackrel{k_{1}}{\longrightarrow} \sim(\mathrm{CH}=\mathrm{CH})_{2}^{*}-\mathrm{CHCl}-\mathrm{CH}_{2} \sim+\mathrm{HCl}
\end{aligned}
$$

Propagation:

$$
\begin{aligned}
& \sim \mathrm{CH}=\mathrm{CH}-\mathrm{CHCl}-\mathrm{CH}_{2} \sim \\
& \stackrel{k_{1}}{\rightarrow} \sim(\mathrm{CH}=\mathrm{CH})_{2}-\mathrm{CHCl}-\mathrm{CH}_{2} \sim+\mathrm{HCl} \quad(9) \\
& \cdot \cdot \cdot \cdot \cdot \cdot \\
& \sim(\mathrm{CH}=\mathrm{CH})_{n}-\mathrm{CHCl}-\mathrm{CH}_{2} \sim \\
& \quad \stackrel{k_{n}}{\rightarrow} \sim(\mathrm{CH}=\mathrm{CH})_{n+1}-\mathrm{CHCl}-\mathrm{CH}_{2} \sim+\mathrm{HCl}(10) \\
& \sim(\mathrm{CH}=\mathrm{CH})_{n}{ }^{*}-\mathrm{CHCl}-\mathrm{CH}_{2} \sim \\
& \quad \stackrel{k_{n}}{\rightarrow} \sim(\mathrm{CH}=\mathrm{CH})_{n+1}^{*}-\mathrm{CHCl}-\mathrm{CH}_{2} \sim+\mathrm{HCl}(11)
\end{aligned}
$$

UF indicates unstable fragments present in the original polymer. $\sim \mathrm{CH}=\mathrm{CH}^{*}-\mathrm{CHCl}-\mathrm{CH}_{2} \sim$ indicates internal chloroallylic groups which formed in the degradation of UF and are present in the original polymer. $k_{0}, \ldots, k_{n}$ represent the constants of rates of reactions.

The termination of a consecutive reaction of dehydrochlorination along macromolecules occurs due to the reactions of inter- and intramolecular cyclization of generated polyenes. ${ }^{5,21,39,40}$

It has been shown ${ }^{41,42}$ that the following reactions of cyclization proceed with low-molecularweight model compounds:<smiles>C=CC=CC=CC1CC2CCCCC(C1)C2C=CCC1CCCCCC1</smiles>

The reactions 12 and 13 have the following Arrhenius parameters: $\log A=11.0, E=29.9 \mathrm{kcal} /$ $\mathrm{mol}^{41} ; \log A=11.0, E=17.0 \mathrm{kcal} / \mathrm{mol}^{42}$

Termination of a dehydrochlorination chain is also possible because of stereochemical reasons, when conjugation of a newly formed double bond with previously generated conjugated double bonds is absent. ${ }^{5,39}$ 
A quantitative treatment ${ }^{21}$ of the represented scheme for the thermal degradation of PVC has been carried out under the conditions that $n=5$, $k_{3}=k_{4}=k_{5}$, and $k_{1}, k_{2}$ and $k_{5}$ are only slightly different, because it has been shown ${ }^{23}$ that in the gaseous phase model compounds with structure $\sim(\mathrm{CH}=\mathrm{CH})_{n}-\mathrm{CHCl}-\mathrm{CH}_{2} \sim$ degrade with approximately the same rate constants if $n=1-3$.

Recently it has been established ${ }^{24}$ that in the thermal decomposition of similar compounds in liquid phase, the following relation of rate constants is observed: $k_{0} \ll k_{1} \ll k_{2}$.

Using the theory of the consecutive reactions, at $k_{0} \ll k_{1} \ll k_{2} \simeq k_{n}$ and $k_{0}{ }^{\prime} \gg k_{1}$ one can obtain eq 14 and eq 15

$$
\begin{aligned}
& \frac{\mathrm{d}[\mathrm{HCl}]_{\mathrm{I}}}{\mathrm{d} t}=k_{0} C_{0}{ }^{0} l_{\mathrm{av}}\left(\mathrm{e}^{-k_{0} t}-\frac{l_{\mathrm{av}}-1}{l_{\mathrm{av}}} \mathrm{e}^{-k_{1} t}\right) \\
& \frac{\mathrm{d}[\mathrm{HCl}]_{\mathrm{II}}}{\mathrm{d} t}=k_{1}\left(C_{0}{ }^{0}+[\mathrm{UF}]_{0}\right) \mathrm{e}^{-k_{1} t}\left(l_{\mathrm{av}}-1\right)
\end{aligned}
$$

where

$$
\frac{\mathrm{d}[\mathrm{HCl}]_{\mathrm{I}}}{\mathrm{d} t} \text { and } \frac{\mathrm{d}[\mathrm{HCl}]_{\mathrm{II}}}{\mathrm{d} t}
$$

are the rates of dehydrochlorination initiated by degradation of normal groups and unstable fragments present in the original polymer, respectively. $C_{0}{ }^{0}, C_{1}{ }^{9}$, and $[\mathrm{UF}]_{0}$ indicate the concentrations of normal links, chloroallylic fragments, and other unstable groups presented in the original polymer. $l_{\mathrm{av}}$ denotes the average chain length of consecutive reactions of dehydrochlorination (eq 6-11) (or average number of double bonds in generated polyenes).

Integration of eq 14 and 15 yields

$$
\begin{aligned}
{[\mathrm{HCl}]_{\mathrm{I}} } & =l_{\mathrm{av}} C_{0}{ }^{0}\left(1-\mathrm{e}^{-k_{0} t}\right)-\left(l_{\mathrm{av}}-1\right) C_{0}{ }^{0} \frac{k_{0}}{k_{1}}\left(1-\mathrm{e}^{-k_{1} t}\right) \\
{[\mathrm{HCl}]_{\mathrm{II}} } & =\left(l_{\mathrm{av}}-1\right)\left(C_{1}{ }^{0}+[\mathrm{UF}]_{0}\right)\left(1-\mathrm{e}^{-k_{1} t}\right) \\
{[\mathrm{HCl}]_{\mathrm{III}} } & =[\mathrm{HCl}]_{\mathrm{I}}+[\mathrm{HCl}]_{\mathrm{III}}
\end{aligned}
$$

where $[\mathrm{HCl}]_{\mathrm{III}}$ is the concentration of $\mathrm{HCl}$ evolved in the thermal degradation of PVC in vacuo. $[\mathrm{HCl}]_{\mathrm{I}}$ and $[\mathrm{HCl}]_{I I}$ are the concentrations of $\mathrm{HCl}$ which form in the consecutive dehydrochlorination initiated by degradation of normal links and of unstable fragments in the original polymer, respectively.
Substitution of eq 16 and 17 in eq 18 yields

$$
\begin{aligned}
{[\mathrm{HCl}]_{\mathrm{III}} } & =l_{\mathrm{av}} C_{0}{ }^{0}\left(1-\mathrm{e}^{-k_{0} t}\right) \\
& +\left\{\left(C_{1}{ }^{0}+[\mathrm{UF}]_{0}\right) \frac{k_{0}}{k_{1}} C_{0}{ }^{0}\right\}\left(l_{\mathrm{av}}-1\right)\left(1-\mathrm{e}^{-k_{1} t}\right)
\end{aligned}
$$

The first term in eq 19 corresponds to curve 2 and the second term to the curve 5 (Figure 1).

The separation of the experimental kinetic curve of dehydrochlorination of PVC in vacuo (Figure 1, curve 1) into curves 2 and 5 gives the possibility of defining the kinetic parameters $k_{0}$ and $k_{1}$.

$k_{1}$ has been calculated ${ }^{5,6}$ from the half-conversion period (Figure 1, curve 5). $k_{1}$ coincides with $k_{\mathrm{a} 11}^{\mathrm{ef}}$ (eq 5).

One can show that

$$
\begin{aligned}
k_{\mathrm{norm}}^{\mathrm{ef}} & =k_{0} l_{\mathrm{av}} \\
l_{\mathrm{av}} & =5-10[43-45] .
\end{aligned}
$$

Substitution of $l_{\mathrm{av}}=8$ defined in ref 45 into eq 20 yields

$$
k_{0}=10^{11.0 \pm 0.5} \times \exp (-38000 \pm R T) \sec ^{-1}
$$

$k_{0}$ and $k_{1}$ coincide with the rate constants for decomposition of the low-molecular-weight models in liquid phase, viz., 8-chlorohexadecane and 8chloro-6-tridecene. This can be seen from Table II and is strong evidence for molecular-ionic mechanism of PVC degradation because the models decompose by the same mechanism. ${ }^{46-49}$

It is of interest to note that the half-conversion period for degradation of unstable groups of PVC

Table II. Values of rate constants $\left(k_{0}\right.$ and $\left.k_{1}\right)$ for the thermal degradation of PVC and model compounds ${ }^{\mathrm{a}}$ in liquid phase at different temperatures

\begin{tabular}{ccccc}
\hline $\begin{array}{c}\text { Temper- } \\
\text { ature of } \\
\text { degrada- } \\
\text { tion, } \\
{ }^{\circ} \mathrm{C}\end{array}$ & $\begin{array}{c}k_{0} \text { for } \\
\text { PVC, } \\
\mathrm{sec}^{-1}\end{array}$ & $\begin{array}{c}k_{0}{ }^{\mathrm{mod}} \text { for } \\
\text { 8-chloro- } \\
\text { hexadec- } \\
\text { ane, } \\
\mathrm{sec}^{-1}\end{array}$ & $\begin{array}{c}k_{1} \text { for } \\
\text { PVC, } \\
\mathrm{sec}^{-1}\end{array}$ & $\begin{array}{c}k_{1}{ }^{\mathrm{mod}} \text { for } \\
\text { 8-chloro- } \\
\text { 6-tri- } \\
\text { decene, } \mathrm{sec}^{-1}\end{array}$ \\
\hline 180 & $10^{-7.3}$ & $10^{-6.9}$ & $10^{-3.8}$ & $10^{-3.8}$ \\
185 & - & - & $10^{-3.8}$ & $10^{-3.8}$ \\
190 & $10^{-6.8}$ & $10^{-6.5}$ & - & - \\
195 & - & - & $10^{-3.5}$ & $10^{-3.5}$ \\
200 & $10^{-6.5}$ & $10^{-6.1}$ & $10^{-3.4}$ & $10^{-3.4}$ \\
210 & $10^{-6.2}$ & $10^{-5.8}$ & $10^{-3.1}$ & $10^{-3.2}$ \\
\hline
\end{tabular}

a Calculated from Arrhenius expressions given by Mayer, et al. ${ }^{24}$ 
(Figure 1, curve 5) is equal to that obtained ${ }^{26}$ for degradation of groups which have chlorine atoms linked with tertiary carbon atoms, in vinyl chloride -2-chloropropene copolymer. This implies equality of the corresponding rate constants.

After substitution of the values of $k_{1}$ and $k_{0}$ in eq 16 and $17,[\mathrm{HCl}]_{\mathrm{I}}$ and $[\mathrm{HCl}]_{\mathrm{II}}$ were calculated (Figure 1, curves 3 and 4).

Curves 3 and 4 (Figure 1) indicate the contributions of each of the two processes of dehydrochlorination initiated by decomposition of normal links (curve 3) and of unstable groups into original PVC (curve 4) to the overall rate of polymer degradation.

Figure 1 shows that unstable groups present in original PVC, make the greatest contribution to the initial rate of dehydrochlorination. In the ideal case, when there are no such fragments, PVC will refrain from degrading only for a definite time which depends upon the degradation temperature: e.g., at $180^{\circ} \mathrm{C}$ for about $50 \mathrm{~min}$, at $200^{\circ} \mathrm{C}$ for about $10 \mathrm{~min}$.

In the thermal degradation of PVC under vacuum (Figure 1) from about 2-\% conversion, the reaction of dehydrochlorination of the normal links of macromolecules is the major stage of initiation of PVC degradation.

To decrease the rate of PVC dehydrochlorination in vacuo with continuous removal of volatile products, it is necessary to reduce the rate of the consecutive molecular-ionic reaction.

The initial rate of PVC degradation may be retarded by reduction of the concentration of unstable groups presented in the original polymer, and by decreasing $l_{\mathrm{av}}$.

The concentration of unstable fragments in the original PVC may be reduced by alteration of the conditions of polymerization (preserving the purity of the monomer and other components of the polymerization system, carefully removing $\mathrm{O}_{2}$ from the polymerization vessel, decreasing the polymerization temperature, and so on), by isolation (lower temperature of drying of the polymer and so on) and storage of the polymer, and also by introduction of special additives in PVC which can deactivate unstable groups by various chemical reactions.

We treated PVC with various compounds to reveal the reagents which would interact with unstable groups and thus decrease their concentra- tion.

Organic phosphites (these substances interact with peroxide and hydroperoxide groups and $\sim \mathrm{C}-\mathrm{CH}=\mathrm{CH} \sim$ fragments of macromolecules of O

$\mathrm{PVC}^{38}$ ), mixtures of organic phosphites with metal chlorides-electrophilic catalysts (metal chlorides increase the reaction of phosphites with chloroallylic groups of PVC macromolecules and conjugated double bonds ${ }^{4,50,51}$ ), organo-tin derivatives of maleic and thioglycolic acids (these compounds interact with the unstable fragments of macromolecules having chlorine atoms in allylic position or near tertiary carbon atoms ${ }^{8}$ ), were tested. These compounds are PVC stabilizers in the thermal degradation of the polymer.

Figure 3 shows that preliminary treatment of PVC with TBP at $50^{\circ} \mathrm{C}$ and $80^{\circ} \mathrm{C}$ or a mixture of TBP with DBTDC at $80^{\circ} \mathrm{C}$ and $150^{\circ} \mathrm{C}$ does not result in any decrease of the initial rate of PVC dehydrochlorination in vacuo.

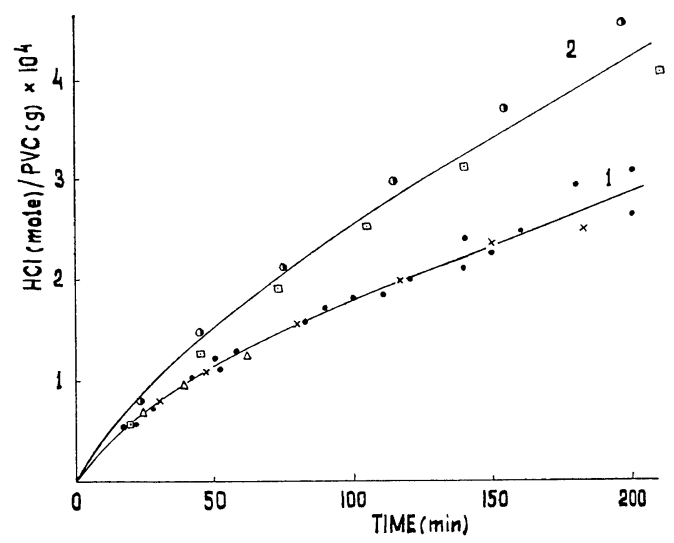

Figure 3. Dehydrochlorination of PVC-I at $200^{\circ} \mathrm{C}$ in vacuo (about $10^{-4} \mathrm{~mm}$ ) with continuous removal of $\mathrm{HCl}$ : (1) original PVC (๑) and PVC treated with $10 \mathrm{~mol} \%$ of TBP at $50^{\circ}$ for $2 \mathrm{hr}(\triangle)$ and at $80^{\circ} \mathrm{C}$ for $5 \mathrm{hr}(\times)$; (2) PVC treated with $10 \mathrm{~mol} \%$ of TBP+1 $\mathrm{mol} \%$ of DBTDC at $80^{\circ}$ for $5 \mathrm{hr}(\square)$ and at $150^{\circ} \mathrm{C}$ for $4 \mathrm{hr}(\mathbf{o})$.

Diminution of the initial rate of degradation of PVC is not observed if the polymer was preliminarily heated in the presence of DBTBBM, DBTBOM, or DBTBBT at $80^{\circ} \mathrm{C}$ and $150^{\circ} \mathrm{C}$ (Figure 4).

It has been shown ${ }^{52}$ that in the thermal degradation of PVC, organo-silicon and organo-germanium hydrides decrease the rate of dehydrochlorination to the rate of PVC degradation under vacuum. 




Figure 4. Dehydrochlorination of PVC-I at $200^{\circ} \mathrm{C}$ in vacuo (about $10^{-4} \mathrm{~mm}$ ) with continuous removal of $\mathrm{HCl}$ : (1) original PVC (0) and PVC treated with $10 \mathrm{~mol} \%$ of DBTBBT at $80^{\circ} \mathrm{C}$ for $5 \mathrm{hr}(\Delta)$; (2) PVC treated with $10 \mathrm{~mol} \%$ of DBTBBT at $150^{\circ} \mathrm{C}$ for $4 \mathrm{hr}$

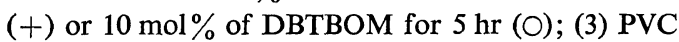
treated by $10 \mathrm{~mol} \%$ of DBTBBM at $150^{\circ} \mathrm{C}$ for $4 \mathrm{hr}$.

In the presence of metal chlorides-electrophilic catalysts the stabilizing effectiveness of hydrides is considerably enhanced. ${ }^{53}$ It was proved ${ }^{53}$ that metal chlorides increase the rate of reaction of reduction of $\mathrm{C}-\mathrm{Cl}$ groups and conjugated double bonds, apparently by the mechanism of hydride transference

$$
\begin{aligned}
& \sim(\mathrm{CH}=\mathrm{CH})_{n}-\underset{\mathrm{C} l}{\mathrm{CH}}-\mathrm{CH}_{2} \sim+\mathrm{MCl}_{m} \\
& \begin{aligned}
\longrightarrow(\mathrm{CH}=\mathrm{CH})_{n}-\underset{\oplus}{\mathrm{CH}}-\mathrm{CH}_{2} \sim \\
\mathrm{MCl}_{m+1}^{\ominus}
\end{aligned} \\
& \begin{array}{c}
\sim(\mathrm{CH}=\mathrm{CH})_{n}-\underset{\oplus}{\mathrm{CH}}-\mathrm{CH}_{2} \sim+\mathrm{HER}_{3} \\
\mathrm{MCl}_{m+1}^{\ominus}
\end{array} \\
& \begin{array}{c}
\longrightarrow \sim(\mathrm{CH}=\mathrm{CH})_{n}-\mathrm{CH}_{2}-\mathrm{CH}_{2} \sim \\
+\mathrm{ClER}_{3}+\mathrm{MCl}_{m}
\end{array} \\
& \mathrm{MCl}_{m}+\mathrm{HCl} \longrightarrow \mathrm{HMCl}_{m+1} \\
& \sim \mathrm{CH}=\mathrm{CH}-(\mathrm{CH}=\mathrm{CH})_{n-1} \sim+\mathrm{HMCl}_{m+1} \\
& \longrightarrow \sim \mathrm{CH}_{2}-\underset{\oplus}{\mathrm{CH}}-(\mathrm{CH}=\mathrm{CH})_{n-1} \sim \\
& \mathrm{MCl}_{m+1}^{\ominus} \\
& \sim \mathrm{CH}_{2}-\underset{\oplus}{\mathrm{CH}}-(\mathrm{CH}=\mathrm{CH})_{n-1} \sim+\mathrm{HER}_{3} \\
& \mathrm{MCl}_{m+1}^{\ominus} \\
& \begin{array}{c}
\longrightarrow \sim \mathrm{CH}_{2}-\mathrm{CH}_{2}-(\mathrm{CH}=\mathrm{CH})_{n-1} \sim \\
+\mathrm{ClER}_{3}+\mathrm{MCl}_{m}
\end{array}
\end{aligned}
$$

where $\mathrm{E}$ is $\mathrm{Si}$ or $\mathrm{Ge} ; n=1,2, \ldots$

We found that after treatment of PVC by TES

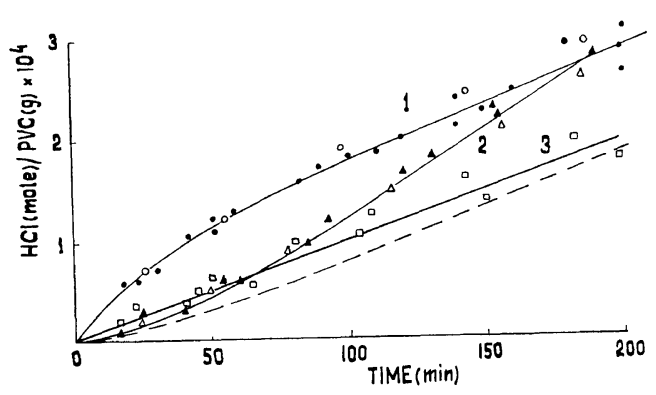

Figure 5. Dehydrochlorination of PVC-I at $200^{\circ} \mathrm{C}$ in vacuo (about $10^{-4} \mathrm{~mm}$ ) with continuous removal of $\mathrm{HCl}$ : (1) original PVC (๑) and PVC treated with $10 \mathrm{~mol} \%$ of TEG at $150^{\circ} \mathrm{C}$ for $4 \mathrm{hr}(0)$; (2) PVC treated with $10 \mathrm{~mol} \%$ of TES $+1 \mathrm{~mol} \%$ of DBTDC at $150^{\circ} \mathrm{C}$ for $2 \mathrm{hr}(\Delta)$ and $4 \mathrm{hr}(\triangle)$; (3) PVC treated with $10 \mathrm{~mol} \%$ of TEG $+1 \mathrm{~mol} \%$ of DBTDC at $150^{\circ} \mathrm{C}$ for $4 \mathrm{hr}$; (-- ), theoretical curve calculated from eq 16 at $k_{0}=10^{-6.84} \mathrm{sec}^{-1}, k^{1}=10^{-3.34} \mathrm{sec}^{-1}$, and $l_{\mathrm{av}}=8$.

or TEG in the presence of catalytic quantities of DBTDC at $150^{\circ} \mathrm{C}$, the initial rate of PVC dehydrochlorination in vacuo decreases considerably (Figure 5). Treatment of PVC with organometal hydrides does not give the same effect (Figure 5).

The decrease of the degradation rate does not correspond to incomplete purification of the polymer. We have used a purification consisting of washings with ether and double reprecipitation. It was checked that the purification caused removal of all hydrides and chlorides. For that purpose, we purified a mixture of PVC with TEG and DBTDC which had not been allowed to react. By atomic absorption spectroscopy, it was shown that the polymer has only traces of Ge and Sn (no more than $1.10^{-3} \%$ by weight).

If thermal treatment of PVC by mixtures of organo-metal hydrides with metal chlorides was carried out, after subsequent purification the polymer also contains about $1.10^{-3} \%$ by weight metals; $i$. e., silicon and germanium are not chemically incorporated into PVC in significant quantities.

According to elementary analysis (Table I), partial reduction of the polymer occurs. For example, during treatment of PVC by mixtures of TEG with DBTDC, a copolymer of vinyl chloride with ethylene (containing about $5 \mathrm{~mol} \%$ ethylene) is formed. Apparently, not only are the unstable fragments present in original PVC reduced, such 
as structures with double bonds, chlorine atoms in allylic position or near tertiary carbon atoms, etc. (eq. 22-26), but also the normal links of the polymer.

It is of interest to note that the initial rate of dehydrochlorination of partially reduced PVC (Figure 5, curves 2 and 3) coincides with the theoretical curve of the polymer degradation initiated by decomposition of normal links of macromolecules (eq 16).

Thus the quantitative treatment of the scheme of consecutive reactions of PVC degradation in vacuo has been carried out. The contributions of each of the two processes of dehydrochlorination, (that initiated by decomposition of unstable groups present in original PVC and that of normal links of macromolecules) into the overall rate of polymer degradation were estimated. An Arrhenius expression is obtained for the rate constant of degradation of normal links (eq 21).

It has been shown that the initial rate of degradation of PVC in vacuo decreases considerably after treatment of PVC by mixtures of Si- or Ge-organic hydrides with metal chlorides-electrophilic catalysts.

Preliminary treatment of PVC with other effective stabilizers, such as synergistic mixtures of phosphites with metal chlorides or organo-tin derivatives of maleic and thioglycolic acids, with subsequent removal of the stabilizers, does not lead to any noticeable improvement of the thermal stability of PVC; $i . e$., these stabilizers show a stabilizing effect only when they are present continually in the thermal degradation of PVC.

Aknowledgment. The authors are very grateful to Professor G. A. Razuvaev for his continued interest in their work, and for useful advice during the discussion of results.

\section{REFERENCES}

1. B. B. Troitskii, "Chemistry and Technology of Macromolecules," Vol. 5, Izdatel'stubo VINITI, Moscow, 1974, p 172.

2. K. S. Minsker and G. T. Fedoseeva, "Decomposition, and Stabilization of Poly(vinyl chloride)," Izdatel'stubo Khimija, Moscow, 1972.

3. D. Braun, Gummi Asbest. Kunststoffe, 24 (9), 902; (10), 1116 (1971).

4. G. A. Razuvaev, L. S. Troitskaya, and B. B.
Troitskii, J. Polym. Sci., Part A-1, 9, 2673 (1971).

5. B. B. Troitskii, L. S. Troitskaya, V. N. Myakov, and A. F. Lepaev, Preprint, International Symposium on Macromolecules, Helsinkii, 1972. Vol. 5, Sect. 4-Sect. 5, S. 1., 189 (1972); J. Polym. Sci., Polym. Symp., No. 42, 1363 (1973).

6. B. B. Troitskii, L.S. Troitskaya, and A. F. Lepaev, Dokl. Akad. Nauk SSSR, 210, 877 (1973).

7. Z. Mayer, J. Macromol. Sci., C10, 263 (1974).

8. G. Ayrey, B. C. Head, and R. C. Poller, Macromol. Rev., 8, 1 (1974).

9. E. N. Zil'berman, "Formation and Properties of Poly(vinyl chloride)," Khimizdat, Moscow, 1968.

10. G. Talamini, G. Cinque, and G. Palma, Mater. Plast. Elast., 30, 317 (1964).

11. G. A. Razuvaev, L. S. Troitskaya, V. N. Myakov, and B. B. Troitskii, Dokl. Akad. Nauk SSSR, 170, 1342 (1966).

12. L. S. Troitskaya, V. N. Myakov, B. B. Troitskii, and G. A. Razuvaev, Vysokomol. Soedin., Ser. A, 9, 2119 (1967).

13. M. B. Neiman, R. A. Papko, and V. S. Pudov, Vysokomol. Soedin., Ser. A, 10, 841 (1968).

14. S. van der Ven and W. F. Witt, Angew. Makromol. Chem., 8, 143 (1969).

15. P. V. Kinney, J. Appl. Polym. Sci., 9, 583 (1965).

16. F. M. Rapoport and A. A. Il' inskaya, "Laboratory Methods of Preparation of Pure Gases," Izdatel'stubo GChI, Moscow, 1963, p. 126.

17. P. M. Zavlin and B. I. Ionin, Zh. Prikl. Khim., 33, 2376 (1960).

18. K. A. Kocheshkov, N. M. Zemljanskii, N. I. Sheverdina, and E. M. Panov, "Methods of Elemento-organic Chemistry. Ge, Sn, Pb," Izdatel'stubo Nauka, Moscow, 1968.

19. K.A. Andrianov, "Methods of Elemento-Organic Chemistry. Si," Izdatel'stubo Nauka, Moscow, 1968.

20. J. Satge, Ann. Chim. (Paris), 6, 519 (1961).

21. B. B. Troitskii, V. A. Dozorov, F. F. Minchuk, and L. S. Troitskaya, Eur. Polym. J., 11, 277 (1975).

22. F. Erbe, T. Grewer, and K. Wehage, Angew. Chem., 72, 988 (1962).

23. V. Chytry, B. Obereigner, and D. Lim, Eur. Polym. J., Suppl., 379 (1969); 7, 1111 (1971).

24. Z. Mayer, B. Obereigner, and D. Lim, J. Polym. Sci., Part C, No. 33, 289 (1971).

25. J. Bauer, and A. Sabel, Angew. Macromol. Chem., 47, 15 (1975).

26. A. R. Berens, Polym. Eng. Sci., 14, 318 (1974).

27. E. N. Zil'berman, E. M. Perepletchikova, E. N. Getmanenko, V. I. Zegel'man, T. S. Molotova, and Ya. A. Zvereva, Plast. Massay, No. 3, 9 (1975). 
28. K. B. Abbäs and E. M. Sorvik, J. Appl. Polym. Sci., 19, 2991 (1975).

29. A. Michel, G. Schmidt, E. Castaneda, and A. Guyot, Angew. Makromol. Chem., 47, 61 (1975).

30. D. Braun and F. Weiss, Angew. Makromol. Chem., 13, 67 (1970).

31. K. S. Minsker, D. V. Kazachenko, R. G. Abdullina, R. B. Kovler, and Al. Al. Berlin, Vysokomol. Soedin., Ser. A, 15, 866 (1973).

32. W. C. Geddes, Eur. Polym. J., 3, 733 (1967).

33. D. Braun and W. Quarg, Angew. Makromol. Chem., 29/30, 163 (1973).

34. A. Caraculacu, O. Wichterle, and B. Scheider, J. Polym. Sci., Part C, No. 16, 495 (1967).

35. G. Boccato, A. Rigo, G. Talamini, and F. ZilioGrandi, Makromol. Chem., 108, 218 (1967).

36. A. Caraculacu, Bezdadea and G. Istrate, $J$. Polym. Sci., Part A-1, 8, 1239 (1970).

37. B. Baum and L. H. Wartmann, J. Polym. Sci., 28, 537 (1958).

38. K. S. Minsker, Al. Al. Berlin, V. V. Lisitskii, and S. V. Kolesov, Plast. Massay, No. 10, 69 (1976).

39. G. A. Razuvaev, B. B. Troitskii, and L. S. Troitskaya, Preprint, the Second International Symposium on Poly(vinyl chloride), Lyon-Villeurbanne, 1976, Topic YII, 261 (1976).

40. T. Kelen, T. T. Nagy, and F. Tüdos, Reaction Kinetics and Catalysis Letters, 1, 93 (1974).

41. K. E. Lewis and H. Steiner, J. Chem. Soc., 3080, (1964).
42. P. Robonson and K. Kholbruk, "Monomolecular Reactions," Izdatel'stubo Mir, Moscow, 1975, p 219.

43. W. C. Geddes, Eur. Polym. J., 3, 747 (1967).

44. D. Braun and M. Thallmaier, Makromol. Chem., 99, 59 (1966).

45. B. B. Troitskii, L. S. Troitskaya, V. N. Denisova, M. A. Novikova, and Z. B. Luzinova, Eur. Polym. $J .$, in press.

46. S. Benson, Termochemical Kinetics, Izdatel'stubo Mir, Moscow, 1971, p 111.

47. F. B. Moin, Usp. Khim., 36, 1223 (1967).

48. F. B. Moin, ibid., 38, 1168 (1969).

49. K. Ingol'd, "Theoretical Bases of Organic Chemistry," Izdatel'stubo Mir, Moscow, 1973.

50. L. S. Troitskaya and B. B. Troitskii, Izv. Akad. Nauk SSSR, Ser. Khim., 2141 (1969).

51. L. S. Troitskaya, B. B. Troitskii, V. N. Denisova, M. A. Novikova, Z. B. Luziniva, and G. A. Razuvaev, "Synthesis and Investigation of Effectiveness of Chemicals-Additives for Polymer Materials," Tambov, 1976, p. 58.

52. V. N. Myakov, B. B. Troitskii, and G. A. Razuvaev, Vysokomol. Soedin., Ser. B, 9, 661 (1969).

53. V. N. Myakov, B. B. Troitskii, and G. A. Razuvaev, "Synthesis and Investigation of Effectiveness of Chemicals-Additives for Polymer Materials," Tambov, 1976, p 56. 